\title{
Estratégias de Segmentação de Hotéis para o Marketing BtoB: um Estudo em São Luís-MA
}

\author{
Hotels Segmentation Strategies for BtoB Marketing: a Study in São Luís-MA \\ Estrategias de Segmentación de Hoteles para el Marketing BtoB: un estudio en São Luís- \\ $M A$
}

Luciana Brandão Ferreira ${ }^{1}$

Ana Akemi Ikeda ${ }^{2}$

\section{Resumo}

O foco deste artigo são as viagens por motivos de negócios, as quais têm grande importância para o desenvolvimento da atividade turística e hoteleira mesmo em localidades com atrativos turísticos naturais e culturais, como é caso da cidade de São Luís-MA. O objetivo foi estudar as estratégias de segmentação utilizadas pelos hotéis para o Marketing Business to Business. Para tanto, realiza-se um estudo de casos múltiplos em dois grandes hotéis da cidade pertencentes a redes hoteleiras internacionais - Pestana São Luís Resort Hotel e Quality Grand São Luís Hotel - por meio de uma pesquisa qualitativa de caráter exploratório. A coleta dos dados primários foi feita por meio de entrevistas pessoais com os gerentes de vendas dos respectivos hotéis. A análise dos casos baseia-se em três pontos principais: a estrutura de marketing dos hotéis, as formas de segmentação utilizadas e as ações de marketing voltadas ao público de negócios. Os hotéis fazem uso de estratégias de segmentação, contudo as utilizam com base em poucas variáveis: volume de vendas atual, potencial de vendas futuro e canal de vendas. As ações específicas para o público de negócios são incipientes, mesmo considerando a grande importância desse mercado.

Palavras-chave: segmentação de mercado; hotelaria; turismo de negócios.

\footnotetext{
${ }^{1}$ Mestre em Administração pela Universidade de São Paulo- USP. Professora Assistente I do Departamento de Turismo de Hotelaria da Universidade Federal do Maranhão-UFMA. E-mail: bfluciana@gmail.com.

${ }^{2}$ Professora Livre Docente de Marketing da FEA/USP. Vice-coordenadora do MBA de Marketing da FIA. Email: anaikeda@usp.br.
} 


\begin{abstract}
The focus of this article are the travels by business reasons, which have great importance for the development of tourism and hostelry even in localities with natural and cultural tourist attractions, as is the case of the city of São Luis-MA. The objective was to study the segmentation strategies used by hotels to Business to Business Marketing. For this, is done a multiple case study in two large hotels in the city belonging to internationals chains Pestana São Luís Resort Hotel and Quality Grand São Luís Hotel - through an exploratory qualitative research. The primary data collection was done through personal interviews with sales managers of the respectives hotels. The analysis of cases is based on three main points: the marketing hotels structure, the forms of segmentation used and the marketing actions directed to the business public. The segmentation strategies are used by the hotels, but they are based in the use of fewer variables: current sales volume, potential of future sales and the sales channel. The specific actions for the business public are incipient, even considering the great importance of this market.
\end{abstract}

Keywords: market segmentation; hostelry; business tourism.

\title{
Resumen
}

El objetivo de este artículo son los viajes por razones de negocios, que tienen gran importancia para el desarrollo del turismo y la hospitalidad incluso en localidades con atractivos naturales y culturales, como es el caso de la ciudad de São Luís-MA. El objetivo es estudiar las estrategias de segmentación utilizadas por hoteles para el Marketing Business to Business. Para este, se lleva a cabo un estudio de caso múltiples en dos grandes hoteles de la ciudad pertenecientes a cadenas de hoteles internacionales, Pestana São Luís Resort Hotel y Quality Grand São Luís Hotel, a través de una investigación cualitativa de carácter exploratoria. La colección de datos primarios se hizo a través de entrevistas personales con los gerentes de ventas de los respectivos hoteles. El análisis de los casos se basa en tres puntos principales: la estructura de marketing de los hoteles, las formas de segmentación utilizados y lãs acciones de marketing dirigidas al público de negocios. Los hoteles utilizan estrategias de segmentación, pero las utilizan baseadas en pocas variables: volumen de ventas actual, ventas potenciales futuras y canal de ventas. Las acciones especificas para el público de negocios son incipientes, aun teniendo em cuenta la gran importância de este mercado.

Palabras clave: segmentación del mercado; hostelería; turismo de negócios.

\section{Introdução}

O turismo pressupõe um deslocamento e uma atividade a ser exercida no local de destino, ou seja, existe uma motivação para a realização da viagem. Segundo Yasoshima e Oliveira 
(2005, p. 41) "As motivações das viagens já mostravam a tendência atual de segmentação, como as viagens de negócios, saúde, religião, cultura, lazer e entretenimento".

Neste artigo, o foco são as viagens por motivos de negócios, tendo por objetivo identificar as estratégias de marketing utilizadas pelos hotéis para a segmentação deste público. Para isso foi escolhido como campo de pesquisa a cidade de São Luís- MA. Optando-se por realizar um estudo de casos múltiplos em dois grandes hotéis da cidade. O período de coleta de informações para esta pesquisa foi em janeiro de 2010.

Um estudo direcionado ao mercado específico de turistas de negócios justifica-se pela importância que é dada a ele e seu grande potencial, seja pelos estudos acadêmicos anteriores, ainda que escassos, ou pelas estatísticas da hotelaria e do turismo.

Segundo os Indicadores Econômicos de Viagens Corporativas -IEVC o faturamento gerado pelo mercado de negócios foi de 21,2 bilhões em $2010,56,67 \%$ do total de viagens do país, gerando 501.774 postos de trabalho, um crescimento de $16,84 \%$ em relação a 2009 . A indústria hoteleira também apresenta resultados bastante positivos. Um exemplo é taxa média de ocupação de 65,95\%, as viagens corporativas somaram $\mathrm{R} \$$ 7,62 bilhões de receitas em 2010. O valor representa $16,32 \%$ a mais que o registrado em 2009. As viagens corporativas totalizam 35,92\% da receita nacional com hospedagem no País. (IVCE, 2010).

Ademais, esse mercado permite uma maior ocupação dos hotéis em períodos de baixa temporada. Aliado a isso, a própria escassez de trabalhos sobre o tema, frente a sua relevância, é motivo suficiente para que haja mais pesquisas a respeito.

A literatura do Marketing Business to Business, tem se dedicado prioritariamente às empresas industriais, existindo poucos trabalhos voltados para empresas de serviços como é o caso dos hotéis. Acrescido a isso, a relevância do público de negócios é percebida mesmo em localidades com atrativos turísticos naturais ou culturais, como é o caso da cidade de São Luís. 


\section{O Turismo de Negócios, a Hotelaria e Segmentação no BtoB}

As motivações para viagens são diversas, mas sem dúvida o lazer e os negócios são as que mais se sobressaem. Viagens para fins de realização de trocas comerciais são antigas e precedem inclusive as viagens por prazer (BARBOSA, 2002). Como muitas definições do turismo relacionam-se com o lazer, existem questionamentos sobre o turismo de negócios ser efetivamente turismo. Contudo, a tendência dos estudos mais atuais é considerá-lo como tal.

Para Davidson (1994), o turismo de negócios refere-se a pessoas viajando com propósito relacionado ao seu trabalho, ele também o considera como a forma mais antiga de turismo. Goeldner e Ritchie (2006), por exemplo, incluem na sua definição de turismo as pessoas que estão participando de convenções, conferências de negócios ou algum tipo de atividade de negócios ou profissional, assim como relacionada a estudos ou pesquisas científicas, já que elas também participam e usufruem da cadeia do turismo.

Wada (2009) subdivide- o em três grandes tipos de acordo com os objetivos do deslocamento: (i) viagens corporativas, aquelas realizadas individualmente, rotineiras e que envolvem grande diversidade de viajantes no que tange a motivos, urgência e duração do deslocamento; (ii) eventos comerciais, onde o deslocamento pode ocorrer de forma individual, mas com um propósito e datas comuns a um grupo (convenções, treinamento, reuniões, entre outros); e, finalmente, (iii) as viagens de incentivos, que embora tenham características de lazer, fazem parte de uma campanha motivacional das empresas dentro de seus negócios, sendo custeadas pelas mesmas.

A importância do mercado de viajantes de negócios pode ser percebida também pelos seguintes fatores: geralmente envolve maior nível de gasto per capita do que qualquer outra forma de turismo; corresponde ao principal mercado da maioria das linhas aéreas e redes de hotéis; necessita de serviços de infra-estrutura e fornecedores especializados o que termina beneficiando o turismo de lazer; é a maior forma de turismo em vários destinos urbanos (SWARBROOKE; HORNER, 2001).

Para entender a demanda pelo turismo de negócios devem ser levadas em conta duas dimensões: a do comprador e a do consumidor. Enquanto no turismo de lazer elas correspondem à mesma figura, no turismo de negócios são entes diferentes, devendo ser considerados pelas empresas turísticas na definição de suas estratégias, já que tanto o 
comprador quanto aquele que consome o produto são importantes no processo de compra e exigem ações diferenciadas.

Apesar da sua importância, ainda existem poucos estudos sobre o turismo de negócios. Realizou-se um levantamento no banco de dados do site do Ministério do Turismo e, de um total de 782 publicações, entre dissertações e teses, apenas nove tratavam no todo ou em grande parte de turismo de negócios: GRAZIADEI, 2002; MARTINS, 1988; SOUZA, 2001; CHAGAS, 2004; MARBACK, 2004; CANOVAS, 2004; WANDERLEY, 2004; SILVA, 2005; MARTIN, 2006. As buscas realizadas em outros bancos de dados também reafirmaram a escassez da literatura sobre o tema.

Dentre os estudos encontrados envolvendo turismo de negócios e hotelaria, observou-se que a grande maioria enfoca o "produto hotel" e que aspectos desse produto são importantes para esse público. Alguns exemplos de temas encontrados dizem respeito: aos determinantes da escolha do hotel, à avaliação da qualidade do serviço, aos aspectos relacionados a níveis de satisfação, às diferenças de importância dada aos atributos conforme o nível dos hotéis, às diferenças nas expectativas e no processo de escolha do hotel para o público de negócios e para o público de lazer, entre outros (WANDERLEY, 2004; GUNDERSEN et al, 1996; MARTINS, 1988; CANOVAS, 2004; GRIFFIN et al, 1996; LEWIS, 1984). Certos atributos do hotel quase sempre aparecem nas pesquisas relacionadas a esse público como relevantes: localização, reputação (marca) e preço (DOLNICAR; 2002).

Segundo Souza (2001), é necessário, ainda, oferecer ao turista de negócios, serviços característicos, como salas de conferências, espaço para reuniões, acesso à internet, transporte alternativo, entre outros. Esses serviços, contudo, estão se tornando padrão na maioria dos hotéis, o que dificulta a diferenciação. Entretanto, para tentar oferecer atributos e serviços diferenciados aos turistas de negócios é necessário antes de tudo conhecê-los, já que é um mercado dinâmico, que apresenta expectativas variadas: o turista de negócios vai desde o alto executivo, até pequenos grupos de trabalho operacional; as empresas possuem políticas de viagens diferentes, há aquelas que utilizam uma agência corporativa e as que efetuam compra direta no hotel por meio de sistemas de gestão de viagens integrados. Todos esses aspectos são importantes para definir as formas de segmentação. 
Embora existam diferenças entre mercado consumidor e mercado organizacional, para Ferrel e Hartline (2008), eles possuem similaridades: ambos possuem compradores e vendedores que querem fazer boas compras e satisfazer desejos pessoais e organizacionais; utilizam processos de compra que possuem estágios de identificação da necessidade, busca de informações e avaliação do produto; e pretendem satisfazer seus clientes.

As diferenças se fundamentam no fato de serem mercados com características distintas e que, portanto, necessitam de tratamentos diversos. A distinção do marketing BtoB para o BtoC inicia-se pela intenção de uso do produto e pelo público que se quer atingir. No BtoC o uso é pessoal, no BtoB ele contribui para a produção de outro bem ou serviço.

Dessa forma, as características específicas de cada um, vão desde o tipo de cliente (natureza do mercado, demanda de mercado, comportamento dos compradores, relação entre compradores e vendedores) e a forma como o cliente usa o produto, já que no BtoB o cliente é uma organização (empresa, governo, instituição), bem como diferenciam-se pelas influências ambientais e pelas estratégias de mercado (HUTT; SPEH, 2002). É principalmente no comportamento de compra que são percebidas as diferenças. A compra organizacional não é um evento isolado, mas um processo de decisão da organização onde existem vários participantes individuais, e, algumas vezes, “os produtos são iguais, mas são necessárias abordagens de marketing fundamentalmente diferentes para alcançar o comprador organizacional" (HUTT; SPEH, p. 34, 2002). Este é o caso da própria atividade hoteleira, onde se trabalha com o mesmo produto direcionando-o aos dois tipos de públicos.

Baseado em Hutt; Speh (2002), pode-se dizer que o serviço hoteleiro é classificado como um produto facilitador para as empresas, já que não entra no processo de produção de outros bens, mas contribui com outros aspectos para o desenvolvimento das atividades da organização compradora. Uma empresa, por exemplo, que tem atividade em várias localidades, precisa alojar seus funcionários, consultores, que tenham necessidade de se deslocar em função da suas atividades, ou ainda na instalação de uma nova unidade, é necessário também o deslocamento e a estada de profissionais para a concretização do negócio, entre outras situações.

Nas relações de troca entre hotéis e empresas, deve-se buscar saber não só quem toma a decisão da compra, mas de que forma ela é tomada, que fatores são levados em consideração 
para a escolha haja vista que por vezes quem decide não é a mesma pessoa que utiliza o serviço, havendo vários influenciadores conforme abordam os principais modelos de compra (ROBINSON; FARIS apud CHOFFRAY; LILIEN, 1978a; WEBSTER; WIND, 1972; SHETH, 1973)

Essas informações podem ser adquiridas por meio de pesquisas de mercado e pelo processo de segmentação, a qual permite conhecer e separar características comuns de determinados públicos e verificar se, de fato, direcionar esforços para estes públicos representa uma vantagem para a empresa.

É em função da crescente diversidade dos mercados que a evolução dos estudos sobre marketing geram a compreensão de que as estratégias de marketing de massa são cada vez mais inadequadas para os dias atuais, sendo mais vantajoso a concentração de esforços em compradores que terão melhores condições de serem atendidos e trarão maior retorno às empresas. O processo de segmentação influencia no desenvolvimento e posicionamento do produto e no desenvolvimento do programa de comunicação (CHOFFRAY; LILIEN, 1978b).

Smith (1956), chama a atenção para um ambiente de mercado caracterizado por uma competição imperfeita, existindo uma diversidade de fornecedores e de demandas do mercado, de forma a serem necessárias estratégias que possibilitassem a convergência da variedade de produtos para as demandas individuais dos mercados.

Sendo assim, um modelo de segmentação requer a seleção de bases de segmentação, ou seja, fatores que melhor caracterizem e captem os desejos de cada segmento. As bases são compostas pelas variáveis dependentes, variáveis usadas para identificar os segmentos, e os descritores são as variáveis independentes, consistem nos critérios que auxiliam na descrição dos vários segmentos (WIND, 1978).

A escolha das bases é a condição fundamental para o resultado da segmentação, já que o sucesso da estratégia está condicionado à capacidade das bases de identificar e categorizar compradores reais e potenciais em grupos que se excluam mutuamente e cujas respostas às ações de marketing sejam relativamente homogêneas (SIQUEIRA, 2005).

As mais conhecidas e utilizadas são: as variáveis geográficas, como diferentes unidades geográficas como nações, estados, regiões, cidades ou bairros; as variáveis demográficas, que 
incluem informações como idade, sexo, renda, ocupação; as variáveis psicográficas, que estão relacionadas ao estilo de vida, personalidade, valores; e as variáveis comportamentais, que se referem ao grau de conhecimento e atitude em relação ao produto (KOTLER; KELLER, 2008).

Haley (1971) cita ainda a segmentação baseada em volume de compra, considerando que um pequeno número de clientes é responsável por um grande número de compras, logo, as estratégias a serem desenvolvidas deveriam considerar tal aspecto. No caso do BtoB essa variável é ainda mais importante que no BtoC, já que é um mercado menos pulverizado.

Contudo, o mesmo autor salienta que, apesar do volume, os benefícios procurados na compra muitas vezes são diferentes, devendo-se levar em conta também variáveis de segmentação relacionadas aos benefícios do produto que estariam dentro das variáveis comportamentais. De fato, o comportamento de compra das empresas é uma importante variável considerada pelos autores para o processo de segmentação no BtoB.

As características das organizações empresariais têm sido aspectos tradicionalmente utilizados pelos profissionais de marketing para a segmentação deste mercado, contudo encontra-se pouca evidência entre as características observadas e o efetivo comportamento de compra (CHOFFRAY; LILIEN, 1978b). Para esses autores, a segmentação pode ser melhor caracterizada pela estrutura do seu processo de decisão de compra. O dois modelos de segmentação mais conhecidos na literatura do BtoB são: o Modelo de Wind e Cardozo (1974) e o Modelo de Shapiro e Bonoma (1984).

O modelo de Wind e Cardozo (1974) baseia-se em duas categorias ou estágios de segmentação: a macrossegmentação e a microssegmentação. A macrossegmentação, como o nome sugere, identifica grandes segmentos, fundamentando-se nas características organizacionais e na situação de compra. Por sua vez, a microssegmentação, que representa o segundo estágio, toma por base a divisão desses macrossegmentos em segmentos menores a partir das características das unidades de tomada de decisão.

O modelo proposto por Shapiro e Bonoma (1984), embora utilize outras nomenclaturas, termina sendo similar ao de Wind e Cardozo (1974). São identificados cinco critérios ou camadas de segmentação: demográficos (tipo de indústria, tamanho, localização); operacionais (tecnologia da empresa/produto; uso da marca, capacidade do cliente); 
abordagens de compra (comportamento do cliente em relação às abordagens de compra); fatores situacionais (urgência do pedido, aplicação do produto, tamanho do pedido); e características pessoais (similaridade ou afinidade entre vendedor e comprador; atitude com relação a riscos; lealdade aos fornecedores).

Elliott e Glynn (2000) propõem uma metodologia de segmentação que alie a valoração dos clientes e suas relações com a empresa vendedora analisando o valor atual e futuro dos segmentos para a empresa e classificando-os em quatro tipos: clientes troca simples, aproveitadores, vendedores e parceiros, conforme o nível de valor e lealdade do cliente. O grande desafio é estabelecer e calcular o valor de cada cliente ou segmento.

Em se tratando do mercado turístico como um todo, Smith (1990) cita duas maneiras básicas de segmentá-lo: a segmentação baseada nos descritores da viagem e a segmentação baseada nos descritores do turista. A primeira organiza o mercado de acordo com os diferentes tipos de viagem, Seaton e Bennett (1996) identificam quatro tipos: recreacional/prazer; visita a amigos/parentes; negócios; e outros. Sendo que cada um desses tipos abrem um novo leque de características e classificações.

No caso do mercado de negócios, por exemplo, dentro dele podem ser feitos questionamentos para identificar novos possíveis grupos, como: “qual o destino?”, “qual o local de atividade?”; “qual o meio utilizado para efetuar a compra (reserva)?” - pela própria empresa, por uma agência de viagens da própria empresa, ou por uma agência externa; "qual a duração da viagem?"; “que tipo de acomodação é utilizada?”; “qual o meio de transporte?”, entre outros (SEATON; BENNET, 1996).

A segunda forma de segmentação fundamenta-se não na viagem, mas na pessoa que faz a viagem, envolvendo perguntas como: "quem é o turista?" em termos sócio-demográficos (idade, ciclo de vida da família, renda, ocupação, sexo), dados psicográficos e estilo de vida (interesses, opiniões, atitudes); “o que ele quer?”, envolvendo dados do benefício do produto (qual a especificação do hotel, quais as características desejadas, que é a segmentação comportamental); "quando ele vem?" Permite definir períodos de alta e baixa estação conforme o tipo de cliente; “de onde?” Envolve dados geográficos (que país, cidade, estado ou região ele é proveniente); e “quanto?" relaciona-se ao volume e freqüência de uso (SEATON; BENNET, 1996). 
Para atuar no mercado de negócios e, conseqüentemente, desenvolver estratégias de segmentação para esse público, a primeira coisa a ser feita é definir quem é o cliente empresarial do hotel. O turista de negócios é, na verdade, o usuário direto dos serviços dos hotéis, já o cliente empresarial é a empresa/instituição que esse turista representa ou que foi responsável por sua estada.

Baseado em Hutt e Speh (2002), pode se dizer que o hotel tem os três tipos de clientes empresariais: as empresas comerciais; os órgãos governamentais e as instituições. No entanto, esses clientes podem ser reunidos em dois grupos, de acordo com a relação que possuem com a atividade turística: empresas que trabalham diretamente com o turismo como as operadoras turísticas e as agências de turismo; e as demais organizações que englobam - as organizações do terceiro setor; o governo e as empresas em geral.

As agências e operadoras, apesar de funcionarem como intermediárias nessa rede, tendo uma importância incontestável no processo de compra, não deixam de ser também consideradas clientes dos hotéis já que ocorre negociação do produto e da tarifa diretamente com elas, em especial as agências corporativas. As empresas organizadoras de eventos devem ser igualmente consideradas clientes empresariais.

O turista de negócios é também classificado em relação à forma de organização das viagens: o corporativo, que viaja pela empresa e o individual, que viaja por iniciativa própria (BRAGA, 2006). Nesses casos, os agentes financiadores e os motivos da viagem podem variar. O primeiro grupo tem suas despesas pagas pela empresa e geralmente utilizam serviços mais caros, sendo mais exigentes, já o segundo opta por alternativas mais econômicas em virtude das restrições financeiras pessoais. (BRAGA, 2006)

Outro ponto que pode diferir os clientes empresariais é a localização e a abrangência da organização: empresas locais, empresas regionais, empresas nacionais, empresas internacionais. Mesmo empresas consideradas totalmente locais, ou seja, instaladas apenas na cidade de destino, podem gerar fluxo de turista de negócios direta ou indiretamente ${ }^{3}$ na

\footnotetext{
${ }^{3}$ Geração de fluxo direto significa que a própria empresa é responsável pela compra da hospedagem, e indireto quando ela não é responsável pela compra, mas sim pela geração da compra através das suas atividades. Ex.: Deslocamento de um funcionário de empresa terceirizada contratada pela empresa local para prestar-lhe serviços.
} 
localidade em função das suas atividades. Contudo, empresas localizadas na cidade, mas com abrangência regional, nacional ou internacional tendem a gerar um fluxo turístico maior.

A importância de estudar estratégias de segmentação direcionadas ao público de negócios pode ser constatada, pelo fato de um mesmo turista de negócios visitar uma localidade com muito mais freqüência do que um mesmo turista de lazer, principalmente se a sua empresa tiver atividades naquele local.

Além disso, esse tipo de cliente termina não se restringindo apenas à utilização dos serviços de hospedagem do hotel, na realidade utiliza vários outros: serviços de eventos, de alimentos e bebidas, de lavanderia, entre outros. Em função dessa freqüência de uso, eles podem ser clientes com um grande potencial de compra para os hotéis. Dessa forma, a segmentação permite a aquisição de informações que servem de base não só para o entendimento do comportamento de compra passado, mas principalmente para a tomada de decisão futura. Um exemplo disso são as ações de relacionamento.

\section{Método da Pesquisa de Campo}

Utilizou-se o método de estudo de caso para responder à seguinte questão de pesquisa: "Como são desenvolvidas as estratégias de segmentação para o mercado empresarial em hotéis de São Luís-MA?”.

A escolha de dois hotéis de grande porte ${ }^{4}$ da cidade foi feita levando-se em conta que em hotéis de médio e pequeno porte ou em pousadas, em sua maioria, não há grande concentração de esforços de marketing para o público de negócios. Isto ocorre em função da própria limitação da estrutura física e organizacional de hotéis desse porte. Além disso, os hotéis pesquisados pertencem a redes hoteleiras o que pressupõe uma maior organização das ações de marketing, já que além das gerências locais possuem o suporte das gerências do grupo hoteleiro como um todo e uma marca forte, consolidada, que segundo pesquisas (DOLNICAR, 2002) é um fator importante para esse público.

\footnotetext{
${ }^{4}$ Consideram-se, neste trabalho, hotéis de pequeno porte aqueles com até 50 unidades habitacionais (UHs), médio porte hotéis com 51 a 100 (UHs), e de grande porte a partir de 101 UHs.
} 
Partindo desse pressuposto tem-se uma justificativa para a escolha do método do estudo de caso, já que não seria possível efetuar o estudo pretendido em qualquer hotel. As limitações do campo escolhido impossibilitariam abordar de forma apropriada o problema de pesquisa, devido à ausência das condições para atestar a teoria (YIN, 2005). Além disso, segundo Yin (2005) esse tipo estratégia de pesquisa é apropriada para as questões do tipo "como" e "por quê" que corresponde à pergunta de pesquisa proposta.

Em relação ao tipo de estudo escolhido, optou-se por uma pesquisa exploratória de abordagem qualitativa. Considerando seus objetivos, uma pesquisa pode ser classificada como exploratória quando se têm pouco ou nenhum estudo anterior em relação ao problema, não fornecem, em geral, respostas conclusivas, e está direcionada para outras pesquisas futuras (COLLIS; HUSSEY, 2005)

Ainda acerca da estratégia de pesquisa, optou-se por um estudo de casos múltiplos. Segundo Herriot; Firestone (1983), citado por Yin (2005), as evidências de casos múltiplos podem ser consideradas mais convincentes que as do caso único e, conseqüentemente, o estudo global é visto como algo mais consistente. Destaca-se, ainda, que nos casos múltiplos considera-se a lógica da replicação e não da amostragem, como se cada caso fosse um experimento específico (YIN, 2005).

Os hotéis foram escolhidos tanto em função das suas similaridades quanto em função das suas diferenças. Ambos são hotéis de grande porte, ou seja, possuem mais de 100 Unidades Habitacionais (UHs) e tem uma estrutura organizacional mais desenvolvida em relação a hotéis de porte menor, além disso, fazem parte de redes internacionais de hotéis. Apesar de não estarem classificados pela EMBRATUR (classificação de estrelas), têm semelhanças quanto ao tamanho e serviços oferecidos, possuindo categoria similar.

No entanto, em relação à localização estão em posições opostas, o primeiro localiza-se na região litorânea e o segundo no centro histórico. Considerando a localização e os próprios atributos de lazer dos hotéis, aliados às características da cidade, eles seriam ideais para o turista de sol e praia e o turista cultural, respectivamente. Contudo, o volume de hospedagem de turistas de negócios é extremamente significativo, mais um motivo pelo qual foram escolhidos para o estudo. 
A coleta de dados nos hotéis se deu por meio de fontes variadas: informações e notícias veiculadas sobre a rede, site oficial do hotel, documentos internos como folders, folhetos informativos e entrevistas com os respectivos gerentes de vendas.

Foram realizadas entrevistas em profundidade do tipo semi-estruturadas com a gerente de vendas do Pestana São Luís Hotel e Resort, com o gerente de vendas do Quality Grand São Luís Hotel em janeiro de 2010. Além dessas entrevistas foram feitos ainda contatos posteriores por telefone e/ou e-mail para dirimir dúvidas que surgiram no momento da análise dos dados.

Esse tipo de entrevista é uma forma de articulação entre outras duas modalidades: a estruturada, que pressupõe perguntas previamente formuladas, e a aberta ou não-estruturada, na qual o tema proposto é abordado livremente (MINAYO, 2003). Também denominada de entrevista semipadronizada, as questões formuladas são abertas e permitem o direcionamento para as hipóteses em questão (FLICK, 2009).

As entrevistas foram realizadas seguindo-se o roteiro previamente definido proposto no protocolo de casos. O roteiro de entrevista se baseou em quatro tópicos: dados da organização; dados do entrevistado; questões relativas a marketing (estrutura de marketing, noções sobre o conceito e aplicação da segmentação, formas de segmentação adotadas e posicionamento); e questões relativas ao público de negócios (importância desse público para o hotel, formas de segmentação adotadas para esse público, ações realizadas a partir da segmentação).

Para o tratamento dos dados foi utilizado a análise de conteúdo, que consiste em uma técnica para estudar e analisar a comunicação de maneira sistemática e objetiva (MARTINS; THEÓPHILO, 2007). As etapas da análise de conteúdo são denominadas por Bardin (2009) de: pré-análise, exploração do material, tratamento dos resultados, inferência e interpretação.

A partir da análise de conteúdo foi elaborado um relatório de cada caso baseado nas seguintes informações: dados da organização de modo a caracterizá-la - nome, histórico da rede hoteleira da qual faz parte, resumo da estrutura organizacional, tamanho em termos de unidades habitacionais, funcionários, taxa média de ocupação; dados gerais do entrevistado; estrutura do setor relacionado ao marketing e formas de segmentação adotadas; e, finalmente, 
questões relativas ao público de negócios do ponto de vista do hotel, importância desse público e estratégias adotadas.

\section{Resultados}

\subsection{O turismo e a hotelaria em São Luís}

Apesar dos atrativos naturais - praias e culturais - conjunto arquitetônico histórico, em termos de oferta hoteleira, São Luís ainda está em desenvolvimento, seus dados de meios de hospedagens à época da pesquisa eram: 74 meios de hospedagens cadastrados na Secretaria Municipal de Turismo, entre hotéis, pousadas, albergues e apart-hotéis, perfazendo um total de 3.299 unidades habitacionais e 6.841 leitos (SÃO LUÍS, 2009a).

Desse total, os hotéis de grande porte correspondem a $13 \%$, ou seja, existem 10 empreendimentos considerados de grande porte (a partir de $101 \mathrm{UHs}$ ), 15 de médio porte (de 51 a $100 \mathrm{UHs}$ ), e a maioria de pequeno porte, 49 hotéis (até $50 \mathrm{UHs}$ ). O desempenho do setor, no que tange à média de taxa de ocupação hoteleira, no ano de 2008 , foi $63,16 \%$, próximo à média nacional (SÃO LUÍS, 2009a).

O fluxo de visitantes na cidade, no mesmo ano, foi de 1,2 milhões de pessoas. O gasto médio per capita foi de $\mathrm{R} \$ 537,73$; a permanência média de 6,8 dias, o que gerou uma receita turística de R \$ 684,31 milhões e renda de R \$ 1.197,54 milhões, correspondendo a 7,4\% do PIB da cidade (SÃO LUÍS, 2009a).

Sobre o turista de negócios foram encontrados poucos dados oriundos das pesquisas de perfil turístico realizadas pela Secretaria Municipal de Turismo de São Luís, já que esta não é direcionada especificamente a esse público.

A pesquisa considera cinco tipos de turistas, tomando por base a motivação da viagem: visita a parentes/amigos; passeio; eventos; negócios/estudos; saúde. O percentual de turista de negócios em relação ao total de turistas varia de $17,7 \%$ a $41,6 \%$. Salienta-se que o período de maior representatividade desse tipo de turista é nos meses de baixa estação ${ }^{5}$.

\footnotetext{
${ }^{5} \mathrm{O}$ trade turístico da cidade considera como alta estação/temporada os meses em que há um grande fluxo de turistas de lazer, principalmente janeiro e julho, que coincidem com as férias escolares, e, baixa temporada, os meses em que há uma redução natural desse tipo de turismo, no caso da pesquisa de perfil: maio e novembro.
} 
Ao se tratar da importância que esses turistas representam para os hotéis, em especial, nos meses de baixa temporada, nota-se que existe um percentual relevante de usuários dos hotéis que correspondem a esse público: $44,7 \%$ e $64,5 \%$, respectivamente. No mês de janeiro de 2009, apesar de ser um mês considerado de alta estação para o turismo de lazer, o público de negócios representou mais de $50 \%$ dos usuários de hotéis. Isso demonstra que, embora haja mais destaque para o período de baixa temporada, esse público está presente nos hotéis também em outros períodos (SÃO LUÍS, 2009b).

Os dados da Secretaria demonstram também que na baixa temporada há um incremento do gasto total do turista de negócios em relação ao turista de passeio, chegando a ser 3,7 vezes maior no caso do mês de novembro de 2007, e 1,5 vezes maior no mês de maio de 2008 .

Outro ponto a ser considerado ao se tratar do turismo de negócios é o grau de desenvolvimento empresarial/industrial da cidade. Sobre este aspecto, de acordo com o IBGE (2006), São Luís possui 29 Indústrias extrativistas; 13 de produção e distribuição de eletricidade, gás e água; 1.096 de construção e 1.335 de transformação. Desse total, apenas 80 estão cadastradas na Secretaria de Estado da Indústria e Comércio do Maranhão. Contudo, esse cadastro prioriza empresas de transformação e, ainda assim, é um número pequeno se comparado ao do IBGE. Logo se subtende que a grande maioria é de pequenas empresas, algumas possivelmente não estão mais em operação, e poucas se cadastram na Secretaria.

A presença de um complexo portuário também contribui para o potencial de negócios da cidade. A proximidade de um porto e a sua estrutura significa uma possibilidade de melhor escoamento da produção, estimulando a implantação de indústrias em uma localidade. De acordo com o Anuário Estatístico Portuário, elaborado pela Agência Nacional de Transporte Aquaviário (ANTAQ), o Complexo Portuário de São Luís, que compreende o Porto do Itaqui e os terminais privados da Vale (Ponta da Madeira) e da Alumar, registrou maior movimento em volume de cargas em 2008. Das 768 milhões de toneladas em todo o país, o Complexo movimentou cerca de 105 milhões, 13\% do total nacional (ANTAQ, 2008).

\subsection{Análise comparativa dos casos}

Os dois hotéis pesquisados fazem parte de grupos hoteleiros. O Pestana São Luís Hotel Resort faz parte do Grupo Pestana, um grupo português que teve sua origem em 1972. A atividade principal do grupo é o turismo, envolvendo não só hotéis, mas também agências, operadoras, 
participação em empresa de vôo charter. O Quality Grand São Luís Hotel faz parte do grupo Atlantica Hotels International que é a maior administradora hoteleira independente de multimarcas da América do Sul. Foi fundada em 1998 por Paul J. Sistare, atual presidente da companhia que detém alianças estratégicas com a Choice Hotels International (proprietária das marcas Sleep, Comfort, Comfort Suites, Quality e Clarion) e com o Carlson Companies (bandeiras Radisson e Park Suítes); possui também marcas próprias, Go Inn e Atlantica Collection, para hotéis independentes.

Atualmente, o Grupo Pestana é o maior grupo português de hotéis. Sua cadeia Pestana Hotels $\&$ Resorts possui 42 unidades em um total de 8.700 quartos, desse total, 9 unidades estão no Brasil. É uma cadeia internacional, com presença, principalmente, em países que tem afinidade com a cultura portuguesa: Portugal, Brasil, Cabo Verde, São Tomé e Príncipe, Moçambique, além de Argentina, Venezuela e África do Sul. Tem previsão de extensão para outros mercados como Inglaterra (Londres), onde um empreendimento já está em andamento.

A rede Atlantica possui sua atenção voltada para o Brasil, com empreendimentos hoteleiros em 40 cidades brasileiras, somando 11 mil apartamentos em mais de 70 hotéis. Diferentemente do Pestana que trabalha com uma categoria única de hotéis, o grupo Atlantica possui um portfólio variado de bandeiras hoteleiras com níveis de conforto diversos. Atualmente, são 10 bandeiras divididas em quatro segmentos diferenciados, conforme serviço e tarifa: Econômico (Go Inn); MidClass (Sleep Inn, Comfort, Park Inn); Superior (Comfort Suites, Quality, Park Suites); Luxo (Clarion, Four Points, Radisson).

Enquanto os hotéis do grupo Pestana são próprios, os do Grupo Atlantica não são de propriedade do grupo, que apenas os administram. O Quality Grand São Luís Hotel é de propriedade familiar, pertencendo a investidores locais. Possui contrato com Atlantica Hotels International desde 2009, que funciona como administradora. O hotel possui 211 unidades habitacionais e 79 funcionários. A oferta de serviços inclui: hospedagem, eventos, almoço/jantar aberto ao público; eventos em ocasiões especiais como dia das mães, dia dos namorados, restaurante, lobby bar, duas piscinas, playground, fitness center, salão de jogos, sauna, salões de eventos.

A unidade Pestana da cidade de São Luís foi inaugurada no ano de 2007. O hotel possui 124 unidades habitacionais, 106 funcionários do próprio hotel e mais 15 terceirizados. Em termos 
de serviços, o hotel oferece: hospedagem, eventos, recreação, SPA (profissional terceirizada, em espaço do próprio hotel), cabeleireiro (terceirizado), agência de viagens, baby sitter agendado.

O primeiro localiza-se no Centro Histórico da cidade e o último na região litorânea. Em relação à estrutura organizacional ambos possuem semelhanças, no caso do Pestana a organização é a seguinte: Gerência Geral, Gerência de Vendas, Gerência de Controladoria, Gerência de A\&B. No caso do Quality a estrutura do hotel é composta basicamente de: Gerência Geral, Gerência de Vendas, Gerência de Manutenção e Controladoria.

As gerências de vendas dos dois hotéis são responsáveis pela captação e gestão de clientes (hospedagem e eventos), coordenação de eventos, gestão de vendas de hospedagem, negociação tarifária, alguns acordos de marketing direcionados às respectivas unidades, negociação com clientes de fora, manutenção da carteira; respondem ainda pelo setor de reservas. A análise dos resultados se baseou nos cinco itens englobados pelas entrevistas conforme segue.

\subsubsection{Estrutura de marketing do hotel e autonomia das decisões em relação à rede}

Fazendo uma análise comparativa dos casos, em relação à estrutura de marketing dos hotéis, nenhum deles possui um setor com a denominação de gerência de marketing, e sim gerência de vendas. No entanto, foi citada a existência de gerência de marketing em cada uma das redes, que dá suporte aos hotéis. Em virtude dos dois hotéis pertencerem a redes, observou-se certa dependência em atender aos requisitos delas, o que de certa forma é bom, pois permite uniformidade nos padrões.

Nos dois casos, a gerência de vendas local responde pela área de marketing do hotel e possui certa autonomia nas decisões a esse respeito em relação à rede, como em aspectos da comunicação, principalmente, em mercados considerados pontuais (mercados de regiões próximas).

No que tange às decisões de marketing, no caso do Quality, que apenas administra o empreendimento, existe ainda a influência dos investidores. As gerências dos dois hotéis possuem a atribuição de definição das tarifas, mas sempre considerando o planejamento da 
rede. Outro ponto similar é a responsabilidade por vendas cruzadas. Nos dois grupos, as gerências possuem metas de vendas de outras unidades hoteleiras das respectivas redes.

\subsubsection{Noções sobre conceito/aplicação da segmentação e formas de segmentação/posicionamento adotadas}

Sobre as noções do conceito de segmentação e sua aplicabilidade, os dois gerentes de vendas parecem ter a noção desse conceito. A segmentação é vista como uma estratégia para auxiliar nas decisões futuras sobre seleção e inclusão de clientes em grupos para diferenciar as ações de marketing e atender melhor às necessidades de cada cliente. Diferentemente do que é posto por alguns autores, como Wind e Cardozo (1974), que enfatizam que, na maioria dos casos práticos, a segmentação parece ser lembrada mais para explicar o pós-fato.

O aumento da concorrência é citado no caso Quality como fator de estímulo ao desenvolvimento das estratégias de segmentação. Um exemplo do entendimento da importância de cada segmento foi citado pela gerente de vendas do Pestana, no qual existe uma prioridade em reservas para clientes mais importantes em termos de volume e relacionamento com o hotel.

A literatura cita a concorrência como um dos fatores estimulantes das estratégias de segmentação (SMITH, 1956), o qual parece ser esse o entendimento dos gerentes entrevistados. Dessa forma, observou-se que os hotéis buscam conhecer seus clientes para segmentá-los, e o público de negócios tem uma grande importância para ambos os casos.

As principais variáveis de segmentação consideradas pelos dois hotéis são o volume de vendas atual e o potencial futuro de vendas que é verificado no momento da negociação tarifária, sendo baseado no volume de hospedagem que a empresa pretende utilizar por determinado período, bem como o canal de vendas: operador, agência, venda direta à empresa. Tarifas menores implicam também em serviços reduzidos, de modo que existe uma negociação específica com cada cliente.

\subsubsection{Importância do mercado BtoB e formas de segmentação adotadas}

Apesar de haver um entendimento da importância do mercado BtoB e da segmentação, não são utilizadas muitas variáveis. O volume de compras do cliente é sem dúvida uma variável essencial, pois possibilita um tratamento diferenciado para os clientes mais lucrativos o que 
concorre para uma política de fidelidade com esses clientes que possuem um uso maior dos serviços do hotel e que geralmente são clientes empresariais. Contudo existem outras variáveis que poderiam ser consideradas como as relacionadas ao usuário, haja vista que ele pode possuir poder de escolha no momento da compra conforme a forma de organização de viagens de cada empresa.

Ao se tratar da segmentação do grupo hoteleiro como um todo, no caso da rede Pestana, não há uma segmentação baseada no tipo de hotel, já que não existe diversidade de bandeiras. $\mathrm{Na}$ rede Atlântica há uma abrangência maior, com segmentos variados baseados no preço e serviço, possuindo um grande número de bandeiras hoteleiras.

Nota-se que não há muita relação entre as variáveis de segmentação encontradas e os principais modelos industriais de segmentação (WIND; CARDOZO, 1974; SHAPIRO; BONOMA. 1984). Uma justificativa para isso pode ser a natureza da atividade, embora tenham clientes empresariais, o serviço hoteleiro não está relacionado à atividade principal das empresas clientes.

Nos casos estudados, observou-se um posicionamento similar em relação à importância da marca, dos atributos e dos serviços que os hotéis oferecem. Mas, segundo os gerentes, tais direcionamentos atendem tanto aos hóspedes de negócios quanto aos de lazer, embora haja algumas ações comerciais diferentes para cada segmento. Nas comunicações de marketing, por exemplo, pode ser feita uma relação entre trabalho e lazer já que não existe comunicação específica para cada tipo de público.

No Quality, o público de negócios valoriza muito a questão de marca. A marca é foi um fator citado como importante para a escolha do hotel pelos turistas de negócios, enquanto o hóspede de lazer visualiza mais a tarifa e a localização do hotel.

Outro ponto importante é o preço, embora sejam hotéis de categorias similares superior/luxo e com um público relativamente parecido, os valores das diárias balcão são diferentes entre os dois hotéis. Contudo, há que se ressaltar que as negociações com os clientes, principalmente os empresariais, incluem também os valores de tarifas, que, dependendo do volume de uso, podem ser reduzidas. 
No que tange à importância do público de negócios, os dois hotéis foram categóricos: é um mercado muito importante. Os percentuais de representatividade na ocupação nos dois casos são altos e similares - 70\% no Pestana e $80 \%$ no Quality . E a importância é percebida não só em períodos de baixa temporada, mas ao longo de todo o ano. Mesmo na alta temporada, o BtoC aumenta, mas não supera o BtoB. A grande importância deste mercado constitui-se em um bom motivo para ações específicas, que, no entanto, ainda são incipientes, principalmente considerando o percentual de faturamento que é bastante significativo.

Observou-se que não há diferenciação citada em relação aos tipos de clientes organizacionais - empresa, governo e terceiro setor (HUTT; SPEH, 2002), não é um fator considerado para a segmentação. O fator realmente importante é a produção de cada cliente. Foram citadas algumas ações similares dos dois hotéis voltadas à política de relacionamento e fidelidade: parcerias com empresas aéreas e outras tipos de empresas, para geração de pontuação por uso do produto e troca por diárias ou passagens. Contudo, não foi observada nenhuma política de relacionamento realmente específica para seus hóspedes de negócios.

A política de relacionamento acaba sendo geral para todos os hóspedes, além disso, é restrita, já que engloba basicamente programas de pontuação por freqüência de uso do produto. Isso pode ser explicado, de certo modo, pelo fato dos casos não considerarem o usuário (hóspede de negócios) como um fator importante na estratégia de segmentação do hotel. As ações de fidelidade terminam sendo, para clientes freqüentes, independente, se são BtoB ou BtoC, porém como há mais BtoB, eles terminam sendo os mais contemplados.

O fato de haver poucas variáveis de segmentação consideradas, com foco grande no volume de compra, dificulta um maior conhecimento acerca de cada cliente, o que inviabiliza uma política mais forte de fidelidade, que englobe não apenas pontuação por uso, mas um atendimento de necessidades específicas de cada hóspede, fazendo-o cativo, visto que o turista de negócios tem uma freqüência de retorno à cidade muito grande.

As formas de segmentação adotadas diferenciam basicamente em lazer e negócios. Dentro do segmento de negócios existem outros subsegmentos relacionados ao volume de compras (HALEY, 1971; ELLIOTT; GLYNN, 2000), bem como ao canal de vendas. De acordo com o volume são definidas tarifas e serviços, e de acordo com o canal são definidas as formas de comunicação, distribuição. 
Dentre os clientes BtoB, as empresas locais possuem importância para os hotéis pesquisados, principalmente no caso do Hotel Pestana, que enfatizou bastante essa importância, ressaltando que alguns dos seus maiores clientes são empresas locais. O Quality não ressaltou tanto a importância das empresas locais, e sim das empresas de fora, embora também concorde que as empresas locais gerem vendas diretas (principalmente organizadores de eventos) e vendas indiretas de hospedagem, por meio de outras empresas que vêm prestar serviços para elas.

Outro ponto levantado é que o Quality diferencia as ações nos segmentos baseadas também no tempo, no período do ano, bem como no tipo de produto vendido. São feitas ações específicas para os clientes BtoB por produto: hospedagem; eventos, em um períodos determinados considerados mais adequados pelo hotel para captação do cliente.

\subsubsection{Ações realizadas a partir da segmentação}

As ações de marketing realizadas pelos hotéis para o mercado de negócios se baseiam nas estratégias de segmentação. A política de preços é baseada no volume de vendas, podendo haver aplicação de tarifas mais baixas para prospecção pelo potencial vendas futuras para as empresas. A política de preços é sempre baseada no futuro. Na distribuição foi citada a existência de empresas que utilizam agências de viagens corporativas, e outras, em que a negociação e a venda são feitas diretamente entre hotel e empresa.

Um ponto que apesar de comentado, não foi enfatizado nas entrevistas é a concorrência. Não foi citada a realização de monitoramento dos hotéis concorrentes, nem para a segmentação, nem para as ações derivadas dela como a política de preços, a distribuição, entre outras.

Principalmente no que tange à política de preços, os concorrentes sempre exercem alguma influência para essa definição, pois para a definição de uma tarifa deve-se considerar não apenas a cobertura dos custos do hotel, e o que o mercado está disposto a pagar, mas também quanto é a média cobrada nesse mercado por um serviço similar.

Os intermediários (agências, operadoras) foram citados como importantes no processo de distribuição; a internet também, tanto para a distribuição quanto para a comunicação, principalmente para o Pestana; assim como as visitas aos clientes, sejam à própria empresa ou às agências e operadoras, e as viagens para contato com intermediários de regiões consideradas importantes (estados próximos), telefonemas e mailings. 
Não foram citadas formas de comunicação específicas para o mercado de negócios. No máximo uma diferenciação de layout na ferramenta utilizada para comunicação e não no conteúdo. As adequações específicas do produto ao público de negócios, quando citadas, foram bastante incipientes e de certa forma questionáveis, pois também atendem a outros tipos de clientes como o fato do hotel ter estacionamento próprio ou internet gratuita.

Outro ponto a ser destacado, que é desconsiderado pelos hotéis, é a importância do usuário dentro do processo de compra, visto que muitas vezes ele pode possuir certa autonomia para decidir em que hotel irá se hospedar dentre os credenciados pela sua empresa. Como existem vários credenciados, seria interessante por parte dos hotéis efetuarem ações específicas voltadas para esse público.

\subsubsection{Sugestão de matriz de segmentação}

A partir dos referenciais teóricos e da pesquisa de campo, criou-se um quadro com sugestões de categoria/variáveis com suas respectivas descrições, que poderiam ser utilizadas como base para auxiliar na identificação dos tipos de clientes de negócios e na conseqüente segmentação desse mercado (Quadro 1).

Optou-se por um resumo de categorias que englobam tanto características da empresa quanto do usuário, apesar de haver uma ênfase nos descritores de viagem, que identificam o comportamento de compra da empresa, haja vista que, a um primeiro olhar, para o mercado empresarial estas informações são bastante relevantes. Em um segundo momento, pode ser feita uma segmentação mais específica dos descritores dos turistas de negócios para identificar seu perfil e reconhecer seu comportamento enquanto usuário, inclusive com informações colhidas da própria FNRH ${ }^{6}$ (Ficha Nacional de Registro de Hóspedes).

\footnotetext{
${ }^{6}$ A FNRH é um documento obrigatório aprovado pela EMBRATUR que teve ser preenchido pelo hóspede para registrar sua chegada no hotel, contém informações como profissão, sexo, idade, entre outros,
} 
Quadro 1- Categorias para segmentação do mercado empresarial hoteleiro

\begin{tabular}{|c|c|}
\hline Categoria/ Variável & Descrição \\
\hline $\begin{array}{l}\text { Tipo de empresa para qual o } \\
\text { hóspede de negócios trabalha }\end{array}$ & $\begin{array}{l}\text { - Empresas comerciais } \\
\text { - Órgãos governamentais } \\
\text { - Instituições sem fins lucrativos }\end{array}$ \\
\hline $\begin{array}{l}\text { Localização geográfica/ } \\
\text { abrangência geográfica }\end{array}$ & $\begin{array}{l}\text { - Empresas locais } \\
\text { - Regionais } \\
\text { - Nacionais } \\
\text { - Internacionais } \\
\end{array}$ \\
\hline $\begin{array}{l}\text { Relação da empresa com a } \\
\text { atividade turística }\end{array}$ & $\begin{array}{l}\text { - Empresas turísticas (operadoras e agências) } \\
\text { - Organizadores de eventos } \\
\text { - Empresas de outros ramos de atividade }\end{array}$ \\
\hline $\begin{array}{l}\text { Disponibilidade da empresa } \\
\text { ou do hóspede em gastar }\end{array}$ & $\begin{array}{l}\text { - Preço não é o principal fator na política de viagens } \\
\text { - Preço é o principal fator da política de viagens }\end{array}$ \\
\hline $\begin{array}{l}\text { Serviços oferecidos por custo } \\
\text { demandado }\end{array}$ & $\begin{array}{l}\text { - Empresas que buscam baixo custo } \\
\text { - Empresas que buscam melhores serviços }\end{array}$ \\
\hline $\begin{array}{l}\text { Volume de compras atual das } \\
\text { empresas }\end{array}$ & $\begin{array}{l}\text { - Grande fluxo de compra de hospedagem } \\
\text { - Médio fluxo de compra de hospedagem } \\
\text { - Pequeno fluxo de compra de hospedagem } \\
\end{array}$ \\
\hline $\begin{array}{l}\text { Potencial de compras futuras } \\
\text { das empresas }\end{array}$ & $\begin{array}{l}\text { - Grande potencial de compras futuras } \\
\text { - Baixo potencial de compras futuras }\end{array}$ \\
\hline Potencial de vendas cruzadas & $\begin{array}{l}\text { - Empresas com negócios e/ou filiais em outras localidades onde existem } \\
\text { outros hotéis da rede } \\
\text { - Empresas locais, mas que possuem um fluxo intenso de viagens para } \\
\text { outras localidades onde existem outros hotéis da rede } \\
\text { - Empresa que não possuem fluxo de viagens intenso para outras } \\
\text { localidades }\end{array}$ \\
\hline $\begin{array}{l}\text { Potencial de compra pelo tipo } \\
\text { de produto: hospedagem, } \\
\text { eventos, alimentação }\end{array}$ & $\begin{array}{l}\text { - Empresas que usam apenas hospedagem } \\
\text { - Empresas que usam hospedagem e alimentação } \\
\text { - Empresas que usam hospedagem, eventos e alimentação } \\
\text { - Empresas que usam eventos }\end{array}$ \\
\hline Forma de compra & $\begin{array}{l}\text { - Empresas que compram direto no hotel } \\
\text { - Empresas que utilizam agências corporativas }\end{array}$ \\
\hline $\begin{array}{lrr}\text { Nível hierárquico } & \text { dos } \\
\text { hóspedes da empresa } & \text { que } \\
\text { utilizam } & \text { serviço } & \text { de } \\
\text { hospedagem } & & \\
\end{array}$ & $\begin{array}{l}\text { - Operacional } \\
\text { - Gerência } \\
\text { - Diretoria/Presidência }\end{array}$ \\
\hline Frequência de uso do serviço & $\begin{array}{l}\text { - Turistas de negócios eventuais } \\
\text { - Turistas de negócios freqüentes } \\
\text { - Turistas de negócios muito frequentes }\end{array}$ \\
\hline $\begin{array}{l}\text { Poder de decisão em relação à } \\
\text { escolha do hotel pelo usuário }\end{array}$ & $\begin{array}{l}\text { - Usuário tem grande liberdade para escolher o hotel dentre os } \\
\text { credenciados pela sua empresa } \\
\text { - Usuário não tem liberdade para escolher o hotel }\end{array}$ \\
\hline
\end{tabular}

Fonte: As autoras

Nota-se que as categorias sugeridas não são mutuamente exclusivas, podendo ser utilizadas diversas concomitantemente para caracterizar o cliente empresarial sob uma série de aspectos. 
Além disso, não esgotam os preceitos encontrados na literatura e servem de norte para os empreendimentos hoteleiros.

\section{Conclusão}

Embora, os achados não possam ser generalizados, nem foi essa a intenção, por se tratar de estudo de casos, podem servir de orientação para situações e casos similares.

Observou-se que os hotéis pesquisados identificam a importância do público de negócios, possuem conhecimento sobre o conceito de segmentação e fazem uso desse tipo de estratégia para esse público. Os dois casos estudados dão atenção especial ao mercado de negócios. A segmentação desse mercado define as estratégias futuras de marketing a serem implementadas, principalmente as relacionadas ao preço (definição de tarifas), ao produto (serviços ofertados) e à promoção (venda pessoal, internet), mas também à distribuição (uso de intermediários, venda direta). Nota-se que existe um entendimento de que a segmentação é uma estratégia utilizada para auxiliar nas decisões futuras, diferentemente do que se vê na literatura que, enfatiza que, embora essa seja a função real da segmentação ela termina sendo mais utilizada pelas empresas para descrever e explicar o comportamento de compra passado.

Nos dois casos, a segmentação é baseada principalmente no volume de compras atual dos clientes, no potencial de compras futuras e no canal de vendas (agência, operadora, venda direta). As variáveis demográficas e psicográficas não são utilizadas para a segmentação desse público, fator já previsto na literatura do marketing BtoB e reafirmado também neste estudo. As variáveis mais utilizadas são as comportamentais, relacionadas ao comportamento de compra dessas empresas. Quanto maior o volume atual ou o potencial de compra futura, mais competitiva pode ser a tarifa acordada. Por outro lado, o nível de serviço oferecido faz parte da negociação sendo definido, entre outras coisas, em função do preço cobrado, um serviço maior implica também em preços mais altos e vice-versa.

Foi identificada a relevância dos turistas de negócios, e, em virtude disso, a necessidade de políticas específicas para esse público por parte dos hotéis, mesmo no caso de São Luís, que é uma cidade com atrativos naturais/culturais. Apesar dos atrativos, os casos demonstram que o turista de negócios representa no mínimo $70 \%$ da ocupação hoteleira ao longo de todo ano, 
com destaque para a importância das empresas instaladas ou em processo de instalação na localidade para a geração de fluxo de turistas de negócios, seja de forma direta ou indireta. Tal aspecto é citado pela literatura e reafirmado pela pesquisa efetuada.

Fazendo uma relação dos resultados com a literatura pesquisada, observou-se que com relação aos principais modelos de segmentação empresarial propostos pela literatura (WIND; CARDOZO, 1974; SHAPIRO; BONOMA,1984), embora estejam voltados para indústrias ou empresas com serviços relacionados à produção industrial, e não a empresas de serviços facilitadores, a exemplo da hotelaria, alguns aspectos foram percebidos nos casos: taxa de uso, valor de uso, estrutura da compra, com destaque especial para a taxa de uso, denominada nos casos de volume de compra, embora existam outras variáveis que poderiam ser também utilizadas.

Um ponto importante é que, considerando que em algumas empresas clientes o usuário escolhe em que hotel vai hospedar-se dentre os credenciados pela empresa, a segmentação deveria englobá-los, envolvendo não só aspectos da empresa em si como o poder de compra, mas também dos usuários por meio de variáveis demográficas, psicográficas e comportamentais sobre deles. A partir disso poderiam ser estabelecidas comunicações contínuas não só para os centros de compra das empresas, mas também para o turista de negócio. Como a comunicação é o item do mix de marketing mais passível que de ser desenvolvido, observa-se uma carência de comunicações específicas para os clientes de negócios, frente à sua importância, bem como de políticas de relacionamento.

Apesar do entendimento da importância da segmentação, e do seu uso para o planejamento de ações futuras, não foram destacadas muitas variáveis utilizadas pelos hotéis, além do volume de compras e do canal de vendas. Como o usuário não é considerado no processo de segmentação, as estratégias desenvolvidas a partir dela terminam ficando basicamente voltados à negociação de preço.

Existem outros pontos que poderiam complementar o processo de segmentação o que contribuiria também para o desenvolvimento das políticas de relacionamento entre hotéis e empresas, dentre eles destaca-se: as características da organização compradora, o valor de uso do produto, a estrutura da compra, o processo de tomada de decisão, os fatores influenciadores da compra, as características pessoais dos usuários, entre outras. Esses pontos 
poderiam auxiliar nas estratégias de segmentação e conseqüentemente nas ações de marketing contribuindo ainda mais para o alcance dos objetivos organizacionais.

\section{Referências}

AGÊNCIA NACIONAL DE TRANSPORTE AQUAVIÁRIO - ANTAQ. Anuário Estatístico Portuário 2008. Disponível em: <http://www.antaq.gov.br/Portal/Anuarios/ Portuario2008/Index. htm>. Acesso em: 10/09/2009.

BARBOSA, Y. M. História das viagens e do turismo. 2. ed. São Paulo: Aleph, 2002.

BARDIN, L. Análise de conteúdo. 4. ed. Lisboa: Edições 70, 2009.

BRAGA, D. C. Turistas de negócios na cidade de São Paulo: um estudo de demanda segmentada. In: Turismo em Análise, v. 17, n1, p. 64-84, maio, 2006.

CANOVAS, M. I. F. O Turismo de negócios e o consumo cultural e de lazer na cidade de Salvador: motivações e atitudes. São Paulo, 2004. Tese (Doutorado em Ciências da Comunicação) - Programa de Pós-Graduação em Ciências da Comunicação, Departamento de Comunicação da Universidade de São Paulo.

CHAGAS, N. T. S. de C. Turismo de negócios e eventos: um estudo sobre a realidade de UberlândiaMG. Dissertação de Mestrado em Geografia. Universidade Federal de Uberlândia: Uberlândia, 2004.

CHOFFRAY, J.; LILIEN, G. Assessing response to industrial marketing strategy. Journal of Marketing. 42, p.20-31, April, 1978a.

3, p. 17-20, 1978b.

A new approach to industrial market segmentation. Sloan Management Review; Spring 19,

COLLIS, J.; HUSSEY, R. Pesquisa em administração: um guia prático para alunos de graduação e pós-graduação. Trad. Lucia Simonini. 2. ed. Porto Alegre: Bookman, 2005.

DAVIDSON, R. Business travel. Londom: Pitman, 1994.

DOLNICAR, S. Business travellers' hotel expectations and disappointments: a different perspective to hotel attribute importance investigation. Asia Pacific Journal of Tourism Research. 7(1), p.29-35, 2002.

ELLIOTT, G.; GLYNN, W. Segmenting industrial buyers by loyalty and value. 16th IMP Conference, Bath, 2000. Disponível em: http://impgroup.org/uploads/papers/52.pdf. Acesso em: 28/05/2009.

FERREL, O. C.; HARTLINE, M. D. Estratégia de marketing. Trad. Mauro C. Silva. São Paulo: Cengage Learning, 2008.

FLICK, U. Introdução à pesquisa qualitativa. Trad. Joice Elias Costa. 3. ed. Porto Alegre: Arumed, 2009.

GOELDNER, C. R.; RITCHIE, J. R. B. Tourism: principles, practices and philosophies. $11^{\mathrm{a}}$ ed. John Wiley \& Sons, 2006.

GRAZIADEI, T. M. Turismo de negócios na cidade de Bauru: estudo de caso. Dissertação de Mestrado em Ciência da Comunicação. Universidade de São Paulo, São Paulo, 2002. 
GRIFFIN, R. K.; LINDA, S.; PAMELA, W. How business travelers discriminate between mid-priced and luxury hotels: an analysis using a longitudinal sample. Journal of Hospitality and Leisure Marketing. 4: p. 63-75, 1996.

GUNDERSEN, M. G.; MORTEN, H.; OLSSON, U. H. Hotel Guest Satisfaction among business travellers. The Cornell Hotel and Restaurant Administration Quarterly. p. 72-81. April, 1996.

HALEY, R.I. Beyond benefit segmentation. Journal of Advertising Research, v. 11, n.4, p.3-8, 1971.

HUTT, M. D; SPEH, T. W. B2B: gestão de marketing em mercados industriais e organizacionais. Trad. Luciana de Oliveira Rocha. 7. ed. Porto Alegre: Bookman, 2002.

INDÍCE ECONÔMICO DE VIAGENS CORPORATIVAS. IVCE 2010. In: Mercado aquecido: viagens corporativas já somam mais de $55 \%$ do turismo nacional. Disponível em: http://web.infomoney.com.br/templates/news/view.asp?codigo=20 49624\&path=/suasfinancas/. Acesso em: jan de 2011.

INSTITUTO BRASILEIRO DE GEOGRAFIA E ESTATÍSTICA. IBGE. Cidades - São Luís: estatísticas básicas do cadastro central de empresas 2006. Disponível em: http://www.ibge.gov.br/cidadesat/topwindow.htm?1. Acesso em: 20/09/2009.

KOTLER, P; KELLER, K. Administração de Marketing. 12. ed. São Paulo: Prentice-Hall, 2008.

LEWIS, R. C. The Basis of Hotel Selection. The Cornell Hotel and Restaurant Administration Quarterl. p. 54-69, May 1984.

MARBACK, H. F. Turismo de negócios como estratégia para reduzir os efeitos da sazonalidade da demanda turística: o caso do Fiesta Bahia Hotel. Dissertação de Mestrado em Administração estratégica. Salvador: Universidade de Salvador, 2004.

MARTINS, A. A. C. Percepção dos empresários e turistas quanto à infra-estrutura e a qualidade dos serviços de turismo. João Pessoa, 1988. Dissertação (Mestrado em Administração) Universidade Federal da Paraíba.

MARTINS, G. de A.; THEÓPHILO, Carlos R. Metodologia da investigação científica para ciências sociais aplicadas. São Paulo: Atlas, 2007.

MARTIN, V. H. S. Turismo de incentivo: eventos e viagens como premiação no Brasil. São Paulo, 2006. Dissertação (Mestrado em Ciências da Comunicação). Programa de Pós-Graduação em Comunicação, Universidade de São Paulo.

MINAYO, M. C. S. Pesquisa social: teoria, método e criatividade. Rio de Janeiro: Vozes, 2003.

SÃO LUÍS. Secretaria Municipal de Turismo - SETUR. O desempenho do turismo em São Luís 2008. São Luís, 2009a.

Secretaria Municipal de Turismo - SETUR. Relatórios de pesquisa de turismo receptivo: jul 2007 a jan 2009. São Luís, 2009b.

SEATON, A. V.; BENNETT, M. M. The Marketing of tourism products: concepts, issues and cases. 1. ed. Cengage Learning EMEA, 1996.

SHAPIRO, B. P.; BONOMA, T. B. How to segment industrial markets. Harvard Business Review. p.1-8 May-June, 1984.

SHETH, J. N. A model of industrial buyer behavior. Journal of Marketing. v. 37, p. 50-53, October, 1973. 
SILVA, G. C. da. Clusters e turismo de negócios e eventos na cidade de São Paulo: um estudo exploratório do setor hoteleiro na região da Avenida Paulista. São Paulo, 2005. Dissertação (Mestrado em Administração). Pontifícia Universidade Católica de São Paulo.

SIQUEIRA, A. B. de. Marketing empresarial, industrial e de serviços. São Paulo: Saraiva, 2005.

SMITH, S. L. J. Tourism analysis: a handbook. Longman, Harlow, Essex, 1990.

SMITH, W. Product differentiation and market segmentation as alternative marketing strategies. Journal of Marketing. 21. p. 3-8, 1956.

SOUZA, W. R. de. O perfil dos gerentes de hotéis voltados ao turismo de negócios: um estudo de caso. Dissertação (Mestrado em Engenharia da Produção). Programa de Pós-Graduação em Engenharia da produção, Universidade Federal de Santa Catarina, 2001.

SWARBROOKE, J. HORNER, S. Business travel and tourism. Butterworth-Heinemann, 2001.

WADA, E. K. Turismo de negócios: viagens corporativas, eventos e incentivos. In: NETTO, Alexandre P.; ANSARAH, Marilia G. dos R. Segmentação do Mercado Turístico: estudos produtos e perspectivas. São Paulo: Manole, 2009.

WANDERLEY, H. A percepção dos hóspedes quanto aos atributos oferecidos pelos hotéis voltados para o turismo de negócios na cidade de São Paulo. São Paulo, 2004. Dissertação (Mestrado em Engenharia) - Programa de Pós-Graduação em Engenharia, Escola Politécnica da Universidade de São Paulo.

WEBSTER, F. E.; WIND, Y. A general model for understanding organizational buying behavior. Journal of Marketing. vol. 36, n², p. 12-19, April, 1972.

WIND, Y. Issues and advances in segmentation research. Journal of Marketing Research, 15, August, p. 317-337, 1978.

WIND, Y.; CARDOZO, R. Industrial Marketing Segmentation. Industrial Marketing Management. 3, p. 153-166, 1974.

YASOSHIMA, J. R.; OLIVEIRA, N. da S. Antecedentes das viagens e do turismo. In: Turismo no Percurso do Tempo. REJOWSKI, M. (Org.) 2. ed. São Paulo: Aleph, 2005.

YIN, R. K. Estudo de caso: planejamento e métodos. Daniel Grassi (trad.) $3^{\text {a }}$ ed. Porto Alegre: Bookman, 2005.

\section{Recebido em: 11/04/2011}

Aprovado em: 15/06/2012 